\title{
Issues of assessment of the surface area effect on irrigated water consumption
}

\author{
Adiljan Atajanov*, Ibrahim Khudaev, Nail Usmanov, and Laziz Babajanov \\ Tashkent Institute of Irrigation and Agricultural Mechanization Engineers, Tashkent, Uzbekistan
}

\begin{abstract}
This article focuses on improving water-saving technologies for efficient use of water resources, the development and recommendation of modern irrigation methods, and assessing the impact of surface area on irrigation water consumption.
\end{abstract}

\section{Introduction}

This study, devoted to developing and implementing technologies and technical tools for the development of scientifically grounded irrigation systems for agricultural crops and their optimal use in cropland, is one of the key issues of economic development of the Republic. State Program on Irrigation and Irrigation of Irrigated Lands for 2019 Research strategy to implement the "Strategy of Action for the five priority areas of development of the Republic of Uzbekistan for the period of 2017-2021" approved by the Decree of the President of the Republic of Uzbekistan dated February 7, 2017, No. P-4947 [1-5].

The main goal of accelerating irrigated agriculture is to increase soil fertility. In irrigated conditions, soil fertility is largely determined by the relief, that is, the area under cultivation. Long-term scientists' research shows that the uneven surface area of irrigated land still does not meet the requirements of accelerating and mechanizing production processes to ensure full use of the land's fertility potential. In this case, huge reserves of increasing the productivity of irrigated crops are hidden. The declining attention of farmers to the description of irrigated land is explained by the failure to assess the relationship between relief status, irrigated water consumption, and crop yields. In this regard, this method assumes a general assessment of the effect of surface area on irrigation water consumption.

This work aims to assess the impact of surface area on irrigated water consumption and achieve a uniform assessment of irrigated water consumption, which depends on the accuracy of the surface area.

The fieldwork of the research work in the Shovot district of Khorezm region (farms "Ergash Ruzimov," "Ishchanov Odilbek") and Gurlan district ("Tulkin-Mirzabek-Asilbek" farm) and Beruniy district of the Republic of Karakalpakstan ("Reyimboy boshliq"). Irrigation sites for the cultivation of irrigated agricultural crops were selected in the pilot fields.

\footnotetext{
"Corresponding author: a.dilatajanov@mail.ru
} 


\section{Methods}

There must be a leveled area for crops with irrigated fields so that the markings do not exceed $\pm 2-3 \mathrm{~cm}$. For crops that are irrigated by barking or licking (chopped, cereal, grass), the slope of the same slope is required. To determine the effect of surface area on irrigated water consumption, the work is performed as follows:

The surface area with an actual deviation of $\pm 3 \mathrm{~cm}, \pm 5 \mathrm{~cm}, \pm 10 \mathrm{~cm}$ from the project surface is prepared to obtain comparable final results. On these prepared sections, the area is divided into 20×20 m squares. Geodetic mapping is carried out on the surface of the area on tops of $20 \times 20 \mathrm{~m}$ [6-8]. The quality control of the works will be carried out after the leveling works are completed, and the leveling is completed. After that, agrotechnical measures, such as furrow removal, planting, etc., are performed. To determine the level of surface area for irrigated water consumption, all three prepared sections are given the same amount of water with different deviations from the project surface to actual surfaces, and the amount of water provided is measured using a water consumption meter.

To determine the uniformity and degree of moisture content, 3 samples are taken from one location along the fence at 10-20 m steps. The distance between the furrows depends on the type of soil, and the location of the drainage in the area from 36 to 54 meters, and the soil sample is taken from a depth of $0.15,30,45,60 \mathrm{~cm}$. then a ground sample is extracted using a hand-operated drill equipped with a grounding receiver.

Each ground sample is placed in a box, weighed on the spot, and the information obtained is recorded in the field log, indicating the order number. The generally accepted methodology determines soil moisture content in the laboratory (drying at $105^{\circ} \mathrm{C}$, weight measurement, humidity calculation). To objectively assess the effect of surface area on irrigated water consumption, an analytical calculation of moisture content, degree, and distance distribution is performed [9-12].

The average moisture content of longitudinal markings (straight line) at the same depth is calculated by the following formula:

$$
w_{c p . c}^{h}=\sum_{i=1}^{n} w_{i} / \mathrm{n}
$$

where $w_{c p . c}^{h}$ is mean moisture content of markings (straight line) at a certain depth, $\mathrm{h}, \%$; $w_{i}$ is measured humidity at a given depth, $\%$;

$\mathrm{n}$ is the number of points where humidity is measured.

The average moisture content in each soil layer is calculated by the following formula:

$$
w_{c p . y}^{h}=\sum_{i=1}^{m} w_{c p . i} / \mathrm{m}
$$

where $w_{c p . y}^{h}$ is average moisture content at depth $\mathrm{h}, \%$; $w_{c p . i}$ is humidity, measured by longitudinal markings (straight line), $\% ; \mathrm{m}$ is the number of average magnitudes measured.

The relative magnitude of the minimum and maximum moisture deflections for each mark (line) and for each depth is calculated by the following formula:

$$
\Delta w_{p . y}^{h}=\frac{\mid w_{c p . c}^{h}-w_{\text {Muн(макс) }}^{h} /}{w_{c p . c}^{h}}
$$

$\Delta w_{p . y}^{h}$ is relative magnitude of the deviation of a certain humidity; $w_{\text {мин(макс) }}^{h}$ are minimum and maximum values of moisture measured at a specified depth, $\%$.

Estimation of uniform soil moisture content is carried out by comparing average moisture content and their relative deviation. 


$$
\begin{gathered}
w_{c h / e}^{0} \leftrightarrow w_{c p . y}^{15} \leftrightarrow w_{c h / e}^{30} \leftrightarrow w_{c p . y}^{45} \leftrightarrow w_{c p . y}^{60} . \\
\Delta w_{p . y}^{0} \leftrightarrow \Delta w_{p . y}^{15} \leftrightarrow \Delta w_{p . y}^{30} \leftrightarrow \Delta w_{p . y}^{45} \leftrightarrow \Delta w_{p . y}^{60}
\end{gathered}
$$

Assessment of moderate soil moisture content on the irrigated site is carried out by categories related to the limited field moisture capacity (LFMC).

Table 1 presents the values of limited field moisture capacity (LFMC) for specific soils.

Table 1. Limited field moisture content (LFMC) values.

\begin{tabular}{|c|c|}
\hline Mechanical composition of soil & Dry soil weight in\% \\
\hline Very light sandy soil & $6-12$ \\
Light loamy soil & $13-20$ \\
Medium loamy soil & $19-25$ \\
Heavy loamy soil & $22-28$ \\
\hline
\end{tabular}

If the actual soil moisture content (ASMC) is within the range of about $5 \%$ and the maximum field depth limit does not exceed 0.7 , the normal soil moisture content is excellent.

Analytically, this condition can be expressed as follows:

$$
\begin{aligned}
& \beta_{\text {actual }}=(1-0.95) \beta_{\max }, \\
& \beta_{\text {actual }}=(1-0.90) \beta_{\max }, \\
& \beta_{\text {actual }}=(1-0.85) \beta_{\max }, \\
& \beta_{\text {actual }}=(1-0.80) \beta_{\max }
\end{aligned}
$$

where $\beta_{\max }$ is closed field moisture capacity; $\beta_{\text {actual }}$ is actual soil moisture content in $\%$ of dry soil weight.

If the actual soil moisture content is within $10 \%$ of the LFMC, moderate soil moisture is considered good.

$$
\beta_{\text {max }}>\beta_{\text {actual }}>0.9 \beta_{\text {max }} .
$$

If the actual soil moisture content is within $20 \%$ of the LFMC, the moderate soil moisture content is considered satisfactory.

$$
\beta_{\text {max }}>\beta_{\text {actual }}>0.8 \beta_{\max }
$$

If the actual soil moisture content is within $30 \%$ of the LFMC, the normal soil moisture is considered to be poor.

$$
\beta_{\max }>\beta_{\text {actual }}>0.7 \beta_{\max } \text {. }
$$

It is considered inadmissible if the actual soil moisture content is more than $30 \%$ above LFMC.

$$
\beta_{\text {max }}>\beta_{\text {actual }}>0.7 \beta_{\text {max }}
$$

Comparing the sample size along the Eatat, we conclude that the soil has been consistently linear. Comparing the sample sizes for all linear signs (furrows), it is 
concluded that the soil is uniformly moist [13-21]. At each depth point on the plane, comparing soil moisture, we conclude that the soil moisture content and moisture level are reached. A table is drawn up for various irrigation methods that use the UC as an indicator to determine the dependence of irrigated water consumption on the level of leveling [15$20]$.

This connection is illustrated graphically to illustrate this (figure 1).

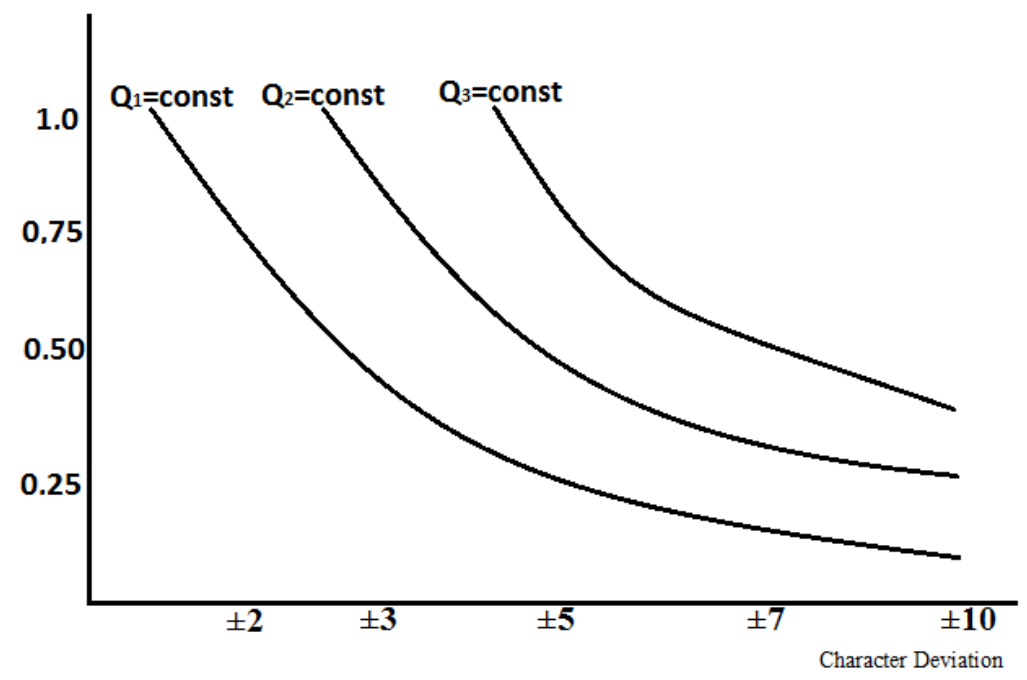

Fig. 1. Water use Graph of the UC for the character deviation (surface leveling)

\section{Results and Discussion}

Technology that allows the density of the furrows to vary in length and depth, even when the surface of the irrigated area is uneven, with its automated work equipment, allows for the precise image of the longitudinal cross-section of the furrow. Uneven compression of soil beneath the bottom of the furrow, that is, elimination of uneven moistening of the rootstratified soil layer due to the maximum and minimum tension at the beginning of the furrow. The proposed technology can be put into production in the early years of development.

\section{Conclusions}

The proposed and developed technology equipment will be used for automated control systems, which will help to reduce water consumption during crop production on irrigated fields, ensure sustainable development of crops and efficient crop production.

\section{References}

1. Decree of the President of the Republic of Uzbekistan dated February 7, 2017 № PF-4947 "Strategy of action on five priority directions of development of the Republic of Uzbekistan in (2017-2021).

2. The Decree of the President of the Republic of Uzbekistan № PP-3405 "On the State Program of Irrigation and Irrigation of Irrigated Lands for 2018-2019". Tashkent, November 27 (2017). 
3. Berdyansky V.N., Atajanov A.U., Method of extraction. Initial Patent No. 1114. July 30, 1997. July. No. 4.

4. Copyright certificate of the Republic of UzbekistanNo. IHDP 9600689.1. (19) UZ (11) 4619 B. (51) 6A 01 G 25/00 1996

5. Cultivator-plant feeding cotton universal KHU-4. M. GOSNITI, (1988).

6. K D Astanakulov, G G Fozilov, B Kh Kodirov, I Khudaev, Kh Shermukhamedov, and F. Umarova Theoretical and experimental results of determination of the peeler-bar parameters of corn-thresher (2020) IOP Conf. Series: Earth and Environmental Science 614(1). DOI:10.1088/1755-1315/614/1/012130

7. Atazhanov A.U. Improving the technology of planning the irrigated field along the furrows. Collection of scientific papers. Tom. 46. series 3.1. 69-71 pp. Ruse. Bulgaria. (2007).

8. Atazhanov A.U. Irmukhamedova L.Kh., Atazhanov A.A. The technology of planning the irrigated field, providing uniform moisture in the soil. The international scientific journal "Young Scientist". G.Kazan. No. 8 (142)/2017 pp. 43-46

9. A Lee, S Allaniyazov, Z Sharipov, B Norov, I Xudaev, and M Sattorov, Cleaning process simulation of the dielectric sorting device (2020) IOP Conf. Series: Earth and Environmental Science ,614 (1), DOI:10.1088/1755-1315/614/1/012124

10. I Khudaev, O Muratov, I Turdibekov and M Yusupov. Technology to restore design parameters of irrigation pump discharge pipelines (2020) IOP Conference Series: Earth and Environmental Science, 883 (1), No. 012046, DOI:10.1088/1757-899X/883/1/012046

11. Atajanov A.U. Technology of preparing lands for irrigating land Scientific journal "Agricultural science", "Agriculture of Uzbekistan". Tashkent. Issue 4 (2007). 25 pages.

12. Atazhanov A.U. New technology and technical means of creating a sustainable profile and design slope of irrigation furrows. Monograph. Printing house TIIAME. (2019) $126 \mathrm{p}$.

13. Atazhanov A. U., Akhmedjanova G.T., Kasymbetova S.A. Problems of developing water and energy saving technologies and equipment Scientific journal "Agricultural science", "Agriculture and water management of Uzbekistan". ISSN 2091-5616 Special Issue No. (2019). pp44-45.

14. Atajanov A.U., Khudayev I.J.Issuesof Developing Water Conservation Technology and Equipment. International Journal of AdvansedResearch in Science, Vol.6, Issue 9, September (2019)

15. Muratov, A., Muratov, O., Melikuziyev, S. Operational control of energy consumptions of reclamation machines (2020) IOP Conference Series: Earth and Environmental Science, 614 (1), DOI: 10.1088/1755-1315/614/1/012042

16. Rakhmonov S., Umurzakov U., Rakhmonov K., Bozarov I., Karamatov O. Land use and land cover change in Khorezm, Uzbekistan. E3S Web of Conferences, 227, 01002, (2021)

17. Umurzakov U., Mamatov F., Aldoshin N., Mirzaev B. Exploration of tillage technologies in the Republic of Uzbekistan, IOP Conference Series, Earth and Environmental Science, 614(1), 012168, (2020)

18. Umurzakov U., and Djuraev B. Prediction of prices for agricultural products through markov chain model, International Journal of Psychosocial Rehabilitation, 24(3), pp. 293-303, (2020)

19. Umurzakov U., Mirzaev B., Salahodjaev R., Isaeva A., and Tosheva S. Energy consumption and economic growth: Evidence from post-communist countries. International Journal of Energy Economics and Policy, 10(6), pp. 59-65, (2020)

20. Lee, A., Usmonov, T., Norov, B., Melikuziev, S. Advanced device for cleaning drain wells. (2020) IOP Conference Series: Materials Science and Engineering, 883 (1), No. 012181, DOI: 10.1088 / 1757-899X / 883/1/012181

21. Matyakubov B., Begmatov I., Raimova I. and Teplova G. Factors for the efficient use of water distribution facilities. IOP Conf. Ser. Mater. Sci. Eng. 883, 012025 (2020) 